\title{
A MULHER PESCADORA NO COTIDIANO DA PESCA ARTESANAL
}

\author{
THE FISHERWOMAN IN THE ARTISANAL FISHING DAYLY ROUTINE \\ LA MUJER PESCADORA EN LO COTIDIANO DE LA PESCA ARTESANAL
}

\author{
Lidiane de Oliveira Goes* \\ Rosineide de Lourdes Meira Cordeiro*
}

\begin{abstract}
RESUMO
Este artigo tem como objetivo discutir o trabalho feminino na pesca artesanal e as classificações profissionais atribuídas às mulheres em duas comunidades pesqueiras em Alagoas. A metodologia consistiu na realização de treze entrevistas com mulheres e homens, em observações nas entidades representativas de classe e na análise das fichas de cadastro dos pescadores. Os resultados apontam que as mulheres participam de toda a cadeia produtiva do setor. Com relação à classificação pescadora, pode-se dizer que essa ora era usada como um conceito amplo que engloba todas as mulheres que trabalham no setor pesqueiro, ora era associada à captura de peixes, trabalho que os homens realizam. Conclui-se que um trabalho educativo e de mobilização nas entidades representativas de classe pode ajudar no reconhecimento das mulheres como profissionais nesse setor.
\end{abstract}

Palavras-chave: Pescadora. Trabalho feminino. Pesca artesanal.

\begin{abstract}
The objective of this article is to discuss the female work in artisanal fishing and the professional classifications attributed to the women in two fishing communities in the state of Alagoas. The study methodology included thirteen interviews focusing women and men, observations at professional representative institutions and the analysis of fishers' registration forms. Results show that women take part throughout the entire productive chain of the sector. Regarding the classification as a fisherwoman, it is possible to say that it is now used as an ample concept, including all women working in the fishing activity and then linked to the fish-catching activity, a task usually associated to the male figure. One concludes that an educational work and mobilization in the professional entities could help in the recognition of women as professionals in this sector.
\end{abstract}

Keywords: Fisherwoman. Female work. Artisanal fishing.

\footnotetext{
Texto recebido em 5 de agosto de 2015 e aprovado para publicação em 15 de setembro de 2016.

Doutoranda no Programa de Pós-graduação em Psicologia Social, da Universidade do Estado do Rio de Janeiro (UERJ). E-mail: lidianegoes@yahoo.com.br.

* Professora doutora no Departamento de Serviço Social e no Programa de Pós-Graduação em Psicologia da Universidade Federal de Pernambuco (UFPE). E-mail: rocordeiro@uol.com.br.
} 


\section{RESUMEN}

Este artículo tiene como objetivo discutir el trabajo femenino en la pesca artesanal y las clasificaciones profesionales atribuidas a las mujeres en dos comunidades pesqueras en Alagoas. La metodología consistió en la realización de trece entrevistas con mujeres y hombres, en observaciones en las entidades representativas de los profesionales de la pesca y en el análisis de las inscripciones en el registro de los pescadores. Los resultados muestran que las mujeres participan de toda la cadena productiva del sector. Con relación a la clasificación pescadora, se puede decir que ésta, bien era usada como un concepto amplio que engloba a todas las mujeres que trabajan en el sector pesquero, como también era asociada a la captura de peces, trabajo que los hombres realizan. Se concluye que un trabajo educativo y de movilización en las entidades representativas puede ayudar en el reconocimiento de las mujeres como profesionales en ese sector.

Palabras clave: Pescadora. Trabajo femenino. Pesca artesanal.

\section{INTRODUÇÃO}

$\mathrm{N}$ os últimos anos, houve uma maior visibilidade das vidas, condições de trabalho e lutas das mulheres pescadoras. Eventos estaduais e nacionais foram realizados, ora promovidos pelos governos estaduais e nacionais, ora por entidades representativas da categoria. Além disso, foram delineadas políticas públicas para a pesca artesanal realizada em regime de produção familiar.

Esse contexto também se apresenta em nível internacional. A Organização das Nações Unidas para a Alimentação e Agricultura (FAO) desenvolve ações de fortalecimento da produção familiar, sobretudo das comunidades tradicionais, como estratégia de diminuição da pobreza no mundo. A mulher, por sua importância na economia das comunidades, é foco dos projetos da FAO, que compreende a discriminação de gênero e, consequentemente, o acesso limitado às mulheres a linhas de crédito, instalaçôes de armazenamento e capacitação como entraves no desenvolvimento da pesca, que é responsável pela manutenção econômica de muito dos grupos familiares no mundo, sobretudo nos países com indicadores de vulnerabilidade social. No Brasil, a FAO mantém um programa que busca atuar na melhoria das políticas públicas referentes à diminuição da pobreza e à garantia dos serviços públicos, bem como o empoderamento das mulheres na produção familiar (FAO, 2019).

Ao contrário dessas iniciativas, as políticas setoriais não têm sido efetivas ao contemplar a questão de gênero. Isso ocorre, sobretudo, por não se considerar a multiplicidade de elementos (trabalho, religião, lúdico) que compõe essas comunidades, enfatizando apenas os objetivos de produção e a geração de renda como qualidade de vida (Maneschy, Siqueira \& Álvares, 2012). 
De acordo com Lima (2003), a participação das pescadoras nas políticas públicas ocorreu em dois momentos: o primeiro, nos meados da década de 1990, sobretudo com a inclusão dos pescadores artesanais como segurados especiais, assegurando os direitos previdenciários a estes, bem como aos membros do grupo familiar (mulheres e adolescentes); e um segundo, caracterizado, no ano de 1995, pela pressão de organizações não governamentais financiadoras das entidades que atuam com a categoria dos pescadores, no I Encontro de Mulheres Pescadoras, em São Luiz-MA. Esses dois acontecimentos também contribuíram para a visibilidade da mulher na pesca. No entanto as mulheres ainda têm dificuldades para serem reconhecidas como profissionais. Como estratégica, Guedes (2007) e Sena (2001) mencionam que algumas mulheres têm se cadastrado nas entidades representativas de classe como pescadoras, a fim de reconhecimento profissional e, consequentemente, acesso a direitos sociais.

De modo geral, a literatura que se dedica a explicitar a participação política das mulheres o faz destacando o engajamento destas em grupos de bairro, em instituições cuja finalidade está situada nas questões de trabalho e, ou, de gênero ou em movimentos sociais como espaços de discussão e organização das mulheres pescadoras. A luta pelo reconhecimento profissional das mulheres resultou na formação, em 2006, da Articulação Nacional das Pescadoras que, além de ser instrumento das reivindicações das mulheres, também diz da constituição de uma posição identitária no setor pesqueiro: a pescadora.

Este artigo tem como objetivo discutir o trabalho das mulheres na pesca artesanal e as classificaçõos profissionais atribuídas às mulheres em duas comunidades de pescadores e pescadoras em Alagoas. Foi tomada como ferramenta analítica o conceito da divisão sexual do trabalho proposto por Kergoat $(2000 ; 2002)$, Hirata e Kergoat (2003) bem como os aportes dos estudos etnográficos sobre o trabalho das mulheres na pesca.

Os conceitos de divisão sexual do trabalho e das relações sociais de sexo ${ }^{1}$ são debatidos e divulgados, no Brasil, no campo das teorias feminista e de gênero, com base nas pesquisas de Kergoat e Hirata ${ }^{2}$. Com a criação, em 2001, do Grupo de Reflexão Feminista sobre o Mundo do Trabalho Produtivo e Reprodutivo, ocorreu uma intensificação de eventos e produção teórica sobre o tema. ${ }^{3}$ De acordo com Hirata (2002) e Kergoat (2000), as relações de sexo e a divisão sexual do trabalho são termos indissociáveis. Na concepção das autoras, as

1 As pesquisadoras francesas usam o termo "relaçôes sociais de sexo" ou "relaçôes sociais de sexo-gênero", em vez de "relações de gênero" ou "gênero".

2 Daniéle Kergoat é socióloga, diretora emérita de pesquisa do CNRS (Centre National de la Recherche Scientifique), diretora emérita de pesquisa em Paris 8 e Paris 10. Helena Hirata é diretora de pesquisa emérita do CNRS, no laboratório Cresppa equipe Genre, Travail, Mobilités (GTM), associado às Universidades de Paris 8-Saint-Denis e Paris 10-Nanterre. Sua pesquisa é voltada para a área de Sociologia do Trabalho e do Gênero.

3 Grupo formado por feministas de organizações não governamentais, do movimento de mulheres, dos sindicatos e de diferentes universidades que investem na organização de seminários e produção teórica sobre o trabalho das mulheres. 
relações de sexo são antagônicas, são construções sociais, têm uma base material e são relações hierárquicas de poder e dominação. Nessa perspectiva, o trabalho abrange o profissional (assalariado ou não, formal e informal) e o trabalho doméstico. Esse trabalho vai além das tarefas domésticas, inclui os cuidados corporais e afetivos com os filhos e filhas, os mais velhos e velhas e uma certa "disponibilidade permanente do tempo das mulheres para a família e os parentes" (Kergoat, 2002, p. 50). Para Hirata e Kergoat (2003), o eixo da dominação e opressão das mulheres é a divisão sexual do trabalho. Na supressão dessa divisão, haveria transformação das relações hierárquicas e antagônicas de sexo.

Segundo Kergoat (2002), divisão sexual do trabalho "caracteriza-se pela designação prioritária dos homens à esfera produtiva e das mulheres à esfera reprodutiva [...] [e] a captação pelos homens das funçôes com forte valor agregado (política, religiosa, militantes)" (p. 50). É estruturada com base em dois princípios: o da separação entre o que é trabalho de homens e trabalhos de mulheres; e o da hierarquia. O trabalho dos homens tem forte valor social, mais do que o trabalho das mulheres, o que favorece que as atividades realizadas pelos homens sejam mais valorizadas do que as das mulheres. Mesmo defendendo que esses princípios podem ser encontrados em várias sociedades, as autoras reconhecem que as modalidades do trabalho de homens e mulheres são variáveis de acordo com o tempo e o espaço. Também reconhecem a importância de estudar as permanências, rupturas e deslocamentos que tendem a questionar a existência dessa divisão.

No que se refere às pesquisas etnográficas e sociológicas sobre o trabalho das mulheres na pesca, as autoras vão acentuar que as mulheres desenvolvem trabalho remunerado e trabalho não remunerado, esse último abrange atividades para o autoconsumo familiar e o trabalho doméstico (Escallier, 1999; Lima, 2003; Maneschy, 1995, 1999; Motta-Maués, 1999; Ribeiro, 2003; Sena, 2001; Vieira, Siqueira, Gomes \& Ever, 2015; Woortmann, 1992).

Para a análise do trabalho das mulheres, Maneschy (1995) sugere a ampliação da compreensão de produção pesqueira. Essa deve englobar as atividades de processamento do pescado, de preparo e de conservação dos instrumentos de pesca, além da captura de espécies, a fim de permitir uma melhor caracterização da atuação das mulheres no setor pesqueiro. De acordo com a literatura, as mulheres, em sua maioria, realizam a pesca de linha de mão e de pequenas redes, coleta de mariscos, a despesca de curral, pesca de polvo, a salga do peixe, a evisceraçãa, a confecção e o reparo de redes e velas de canoa, e a comercialização de peixes. Tais atividades, geralmente, ocorrem em áreas cuja proximidade se refere à terra e, ou, à casa (rios, lagos, manguezais e praias), enquanto as realizadas pelos homens ocorrem quase sempre em mar alto (Maneschy, 1995). 
Para Woortmann (1992), essa oposição entre os espaços terra/mar corresponde à oposição entre mulher/homem, a qual se refere à divisão sexual do trabalho.

A divisão sexual do espaço é algo aprendido desde cedo pelo processo de socialização (Diegues, 1983; Lima, 2003; Maneschy, 1995; Motta-Maués, 1999). A socialização da mulher estaria relacionada a um saber ligado à terra (a casa, o roçado), enquanto a do homem ocorre pela aquisição de conhecimento acerca do manejo dos apetrechos de pesca, do navegar, do movimento das marés (Diegues, 1983; Lima, 2003). Nesse sentido, convém falar que é pelo processo de socialização que as atividades exercidas por homens e mulheres são naturalizadas, assim como os espaços de atuação (Woortmann, 1992).

Diante disso, Lima (2003) menciona que a realização das atividades pesqueiras bem como a de outras atividades extra domésticas pelas mulheres é realizada de acordo com as necessidades do grupo familiar. As mulheres, geralmente, realizam os seus afazeres domésticos antes de saírem para a roça ou para a pesca. Em outras palavras, as mulheres tendem a conciliar a realização das atividades pesqueiras às domésticas.

Essa conciliação, de acordo com a autora, quando não acompanhada pela conscientização de que as mulheres realizam várias atividades, dificulta o seu reconhecimento como trabalhadoras. Maneschy (1995) menciona o fato de algumas mulheres não considerarem como trabalho o que fazem na pesca, na agricultura, pois, muitas vezes, essas atividades são realizadas para parentes e no âmbito doméstico. Assim, quando as atividades não têm valor econômico, são desqualificadas e não recebem o status de trabalho (Lima, 2003).

Além do trabalho doméstico e da pesca, as mulheres também realizam atividades em outros setores, tais como a indústria, o turismo e o de serviços gerais (Escallier, 1999; Lima, 2003; Maneschy, 1995, 1999; Woortmann, 1992). A realização de atividades em outros setores é uma forma de garantir a sustentabilidade do grupo familiar, uma vez que os ganhos da atividade pesqueira realizada por seus maridos são incertos devido ao período de entressafra e às regras de partilha que caracterizam a pesca artesanal (Escallier, 1999; Maneschy, 1995). Entretanto a realização dessa multiplicidade de atividades, além da invisibilidade do trabalho feminino, também ocasiona a sobrecarga (Lima \& Leitão, 2014) e a precarização do trabalho feminino, contribuindo para pauperização desse segmento social.

Apesar da intensa carga de trabalho, o trabalho das mulheres é pensado como ajuda. Isso acontece porque a pesca é definida pela identidade do grupo social que, por sua vez, é constituída com base na figura masculina: o pescador (Woortmann, 1992). Essa condição de ajuda, de complementar dada ao trabalho feminino pode se expressar nas diversas classificações atribuídas às mulheres 
que são e se reconhecem como marisqueiras, pescadeiras, catadeiras, mulher de pescador, trabalhadeiras, rendeiras, etc.; raramente como pescadoras.

O fato de não se reconhecerem as atividades realizadas pelas mulheres nas comunidades pesqueiras, sejam estas por estarem designadas à esfera reprodutiva, logo desvalorizadas (Lima, 2003), sejam por estarem na esfera produtiva, associadas à ideia de complementaridade, constitui o argumento da invisibilidade do trabalho feminino no setor pesqueiro. No entanto MottaMaués (1999) também menciona outro tipo de invisibilidade situada no âmbito das políticas públicas, da sociedade em relação à comunidade pesqueira que afeta tanto homens como mulheres. Esta diz respeito à ausência da participação política nas decisões implementadas pelo governo no setor pesqueiro ao longo dos anos.

\section{PROCEDIMENTO METODOLÓGICOS}

Pesquisa qualitativa com o uso de entrevistas, observação participante e pesquisa documental. Foram realizadas entrevistas semiestruturadas com 9 mulheres e 4 homens, entre 30 e 63 anos de idade, moradores dos bairros de Ipioca e no Trapiche da Barra, no Município de Maceió-AL.

O roteiro de entrevista contemplou os seguintes temas: classificação profissional dada às mulheres que atuam no setor pesqueiro, caracterização da atividade pesqueira, dificuldades e desafios e participação política das mulheres. Apenas uma das entrevistas foi realizada na Colônia ${ }^{4}$ de Pescadores e Marisqueiras Z-16, enquanto que as demais nas residências dos entrevistados.

Com relação à escolha destes, foi aplicada a técnica bola de neve. Essa consistiu, inicialmente, na identificação de algumas pessoas que realizavam atividades pesqueiras, denominadas interlocutores-chave que, posteriormente, indicaram outras. Estas, por sua vez, também indicaram outras, e assim, sucessivamente, até que as informações obtidas fossem suficientes para a pesquisa (Alves, 1991). As entrevistas foram gravadas e, depois, transcritas.

A observação participante foi realizada durante um mês, duas a três vezes por semana, na colônia de pescadores do Trapiche da Barra e no anexo à casa da presidente da Associação de Maricultores Anjos do Mar, em Ipioca. As atividades pesqueiras realizadas pelas mulheres, a participação política e o acesso a direitos sociais foram o foco da observação. $\mathrm{O}$ registro desta consistiu na elaboração de um diário de campo após se deixar o local.

Durante o período de observação, foi realizada a pesquisa documental que consistiu na análise das fichas de cadastro profissional de homens e mulheres 4 Entidade representativa da classe profissional de homens e mulheres que trabalham na atividade pesqueira. 
pertencentes à colônia do Trapiche da Barra. Nessas fichas, buscou-se analisar as classificações profissionais dada às mulheres e o momento em que essas definições começaram a ser usadas.

Realizadas as transcrições das entrevistas, a análise qualitativa e temática das informações geradas consistiu numa leitura das entrevistas e do diário de campo, com o intuito de entender o significado e os temas recorrentes nas falas dos participantes. Posteriormente, elegeram-se os seguintes tópicos de análise: o trabalho das mulheres, o modo como estas eram categorizadas profissionalmente e a participação das mulheres na colônia (quando, por que e como as mulheres procuravam a entidade). Esses tópicos foram escolhidos considerando o roteiro de entrevista, os objetivos da pesquisa e os temas sobre o trabalho de homens e mulheres realizados na pesca. Para auxiliar a análise das classificações profissionais, foi construído um glossário com as atribuições dadas às mulheres, os significados e o local de produção desses.

\section{RESULTADOS E DISCUSSÃO}

As entrevistas, a observação e o estudo das fichas de cadastro profissional demonstraram que as mulheres, em Ipioca e no Trapiche da Barra, participam de toda cadeia produtiva do setor pesqueiro: captura de espécies, o beneficiamento e a comercialização do pescado, conforme a literatura sobre o trabalho feminino na pesca.

Ao serem indagadas sobre o tempo de atuação na atividade pesqueira, algumas mulheres mencionaram que trabalham desde a infância ou juventude na companhia de seus parentes. Assim menciona Denise (46 anos, Trapiche da Barra): "Minha filha, desde de novinha. Vendia, depois tratava peixe, mororó. Passava a noite toda tratando. Aí meu marido trabalhava de vigia, a gente passava a noite, amanhecia o dia, tratando mororó, mandim, sururu".

As mulheres realizavam parte de seu trabalho dentro e, ou, nas proximidades do ambiente doméstico. Elas iniciavam suas atividades à beira da lagoa, praia ou no mangue, mas davam continuidade a elas em suas casas, com a ajuda de seus familiares. Essa é uma característica da pesca artesanal, cujo trabalho das mulheres, crianças e idosos livra o pescador da despesa com o pagamento a terceiros pela realização da atividade (Maneschy, 1995).

Assim também ocorre com as atividades realizadas pelas mulheres em Ipioca e no Trapiche da Barra, o que significa que quanto mais pessoas engajadas na atividade, maior será a produção e menores as despesas. Além disso, o trabalho familiar possibilita o ensino acerca da atividade pesqueira, que é passada de 
geração a geração. Apenas uma das entrevistadas em Ipioca relatou não ter familiares que se ocuparam da atividade pesqueira. Os demais mencionaram ter aprendido o ofício com os pais.

Essa característica confirma que é pela socialização de meninos e meninas que vão sendo aprendidos os conhecimentos acerca do que é atividades de homens e de mulher (princípio da separação na divisão sexual do trabalho). Aos meninos seriam dirigidos conhecimentos pautados num saber relacionados ao mar, às marés, aos ventos, aos cardumes de peixes, aos instrumentos de pesca; para as meninas, o saber estaria ligado à terra, a cuidar da casa, dos filhos, do marido, do roçado (Lima, 2003; Motta-Maués, 1999; Woortmann, 1992). Posteriormente isso caracterizará a distinção de tarefas destinadas aos homens e às mulheres. No entanto, quando as mulheres não seguem esse padrão, são criticadas pela própria vizinhança que, com insinuações, maledicência, desqualificação da atividade pesqueira realizada pelas mulheres como algo feio, errado e imoral. Marisa (50 anos, Ipioca) contou que, apesar de muitos verem-na pescando, as pessoas a ignoravam e falavam que era feio uma mulher pescar.

Parece que a maledicência, as insinuações relacionadas ao trabalho das mulheres estão associadas à praia como local de namoro e de passeios românticos (Woortmann, 1992). Nesse sentido, a maledicência afasta homens e mulheres de desenvolverem atividades conjuntas, permitindo apenas a participação de crianças e de outras mulheres na realização da pesca feminina. Além disso, contribui para a permanência de forte divisão sexual do trabalho pesqueiro.

Em Ipioca, estar na companhia de alguém durante a realização da pesca servia a dois propósitos: o da ajuda na lida da pesca, que pode exigir muito esforço físico, e o de uma proteção diante da violência. "Ter uma companhia, às vezes, é porque [...] É longe. E se sai na parte da noite, do jeito que está hoje [...] E outra, porque ajuda. Uma ajuda para tá apanhando as redes só, porque pesa muito" (Ronaldo e Fernanda, respectivamente, 48 e 45 anos, Ipioca).

Esse aspecto da violência não aparece na literatura sobre o trabalho das mulheres na pesca. Nas entrevistas, a violência podia ser generalizada, possível atingir a qualquer pessoa e, ou, direcionada às mulheres. Em Ipioca, uma pescadora relatou o medo de as mulheres serem atacadas. "É porque, às vezes, elas dizem que eu tenho coragem é por causa que o mundo tá assim, muito marginal solto. Aí, elas têm medo que apareça um marginal na praia, que dê carreira em mim" (Simone, 46 anos, Ipioca).

Além da violência e do aspecto da maledicência relacionados ao trabalho, observaram-se outros aspectos, como a frequência e a geração de renda na caracterização da pesca. A esse respeito, Ana (45 anos) e Denise (46 anos), ambas 
do bairro do Trapiche da Barra, ao serem questionadas se consideravam suas atividades como trabalho, responderam, respectivamente: "Eu considerava como trabalho, porque era um ganho. Era o pão para ajudar no sustento de casa"; "Era! Trabalho digno. Era um trabalho honesto que a gente trabalhava, mas também ficava trabalhando, recebia o ganho do dia para fazer o dinheiro".

Quanto à frequência, Tom (63 anos, Ipioca) relatou que esse aspecto caracteriza o profissional da pesca, ao falar que, apesar da existência de várias mulheres na pesca de maçunim, existe uma que pode ser considerada profissional. Essa seria aquela que o interlocutor vê com mais frequência realizando essa atividade. Vale destacar que a mulher a que Tom se refere também trabalhava como empregada doméstica.

A presença diária na extração de mariscos pode estar relacionada à coleta de outros animais pertencentes ao mesmo grupo. Essa ideia seria a mais possível, visto que se se dedicasse apenas à pesca de um tipo marisco, a atividade não seria tão intensa porque depende da maré. Em média, são duas horas diárias que as mulheres se dedicam a coletar mariscos, pois a maré sobe e cobre quase toda a praia. Para algumas mulheres, significa que as demais horas do dia ficam livres para realizar outras atividades que podem ser relacionadas ao beneficiamento, à venda do marisco, ou as que estão fora do setor pesqueiro, como a realizada por Simone (46 anos, Ipioca): "Quando a maré tá boa, os cinco dias. Que não tem outra coisa [...] para fazer. Agora assim, se aparecer outro serviço (faxina), eu tiro assim uns três dias".

Essa situação não indica que as mulheres estão se afastando da atividade pesqueira e se engajando em outros setores como o de turismo, conforme observado nas comunidades do Pará e do Rio Grande do Norte, estudadas por Maneschy (1995) e Woortmann (1992). As mulheres em Ipioca e no Trapiche da Barra realizam uma multiplicidade de atividades como serviços gerais, confecção de bolos para festa e as de caráter agrícola (coleta e venda de frutas), além das relacionadas à pesca. No entanto, na comunidade da Baía do SolPA, Lima (2003) observou que a existência da associação entre as atividades extradomésticas (pesqueiras, agrícolas e de serviços gerais) e as domésticas ocasionava a invisibilidade das mulheres no setor pesqueiro. Nenhuma de suas atividades eram reconhecidas como trabalho.

Apesar da literatura apontar que as mulheres realizam a conciliação da pesca com outras atividades, em Ipioca e no Trapiche da Barra, os homens também o fazem, conforme mencionado por Milton (53 anos, Ipioca) sobre os diversos trabalhos que realizou. "Eu trabalhava de enxada. Trabalhei bastante de enxada. Plantei muitas canas-caianas. Plantei muita roça, muito feijão. Eu tirei muito 
cocos. Agora, quando eu tirava o coco, que parava o coco, eu ia começar a pescar". Essa associação de atividades da pesca com outras atividades, no caso dos homens, ocorreria entre os períodos de entressafra da pesca e a agrícola. Com relação às mulheres, a realização da pesca com as atividades domésticas era entendida como natural, associada à maternidade, ao lar e aos cuidados com os filhos.

Outro aspecto referente à realização das atividades de pesca para homens e mulheres é a falta do registro profissional. Das 13 pessoas entrevistadas nas duas localidades, apenas 5 delas o tinham.

Em Ipioca, a presença de um cadastramento de pessoas que realizam atividades pesqueiras é recente e realizado por iniciativa da associação de maricultoras. De acordo com a presidente dessa instituição, naquela localidade, existem pescadores com idade para serem aposentados. Alguns, como Milton, encontram-se doentes, sem condiçóes de trabalhar na pesca e sem outro meio de sustento. Lima (2003), em seu estudo, apontou que a população pesqueira recorre à Previdência Social apenas quando estão idosos, em idade para pedir aposentadoria.

A presença de algum problema de saúde no cotidiano de homens e mulheres que realizam a atividade pesqueira é algo constante. As dores nas costas, os problemas na visão surgem ainda na juventude, como relatou a filha de Izabel. Esses são resultado do esforço constante e da exposição do corpo durante a realização da atividade pesqueira. Sem assistência médica e social, a tendência é o agravamento da saúde com o passar do tempo, podendo ocasionar a impossibilidade da realização da pesca.

Apesar das queixas relacionadas à saúde, Izabel, assim como os trabalhadores da pesca, dribla a doença e estabelece outras formas de atuar no setor pesqueiro (beneficiamento e venda do pescado). Essa batalha diária, conforme referida por Maués e Motta-Maués (1990), configura um modo de vida voltado para a provisão do grupo familiar, seja na obtenção de dinheiro com a venda do pescado ou na utilização deste para o consumo. Finalidade essa mencionada pelas mulheres de Ipioca e do Trapiche da Barra como motivadora para o trabalho na pesca.

Além de causar problemas de saúde, o peso também é apontado pelas mulheres como dificuldade no trabalho, principalmente na retirada de mariscos. Tal dificuldade está relacionada ao trajeto feito da praia/lagoa para casa, carregando o marisco (sururu, maçunim) em baldes, latas na cabeça e nas mãos, e, ou, com auxílio de carro de mão e bicicleta. No entanto nem todas as mulheres utilizam esses meios para transportar seus produtos, o que torna penoso o trajeto. 
A situação agrava em Ipioca pela falta de acesso à praia, cercada por sítios, hotéis e condomínios que impedem o acesso da população local, obrigando as pessoas que atuam na pesca artesanal a fazerem longos percursos até chegarem a seus locais de pesca. No Trapiche da Barra, a distância dos locais de pesca para as residências faz com que famílias que vivem da atividade pesqueira busquem moradia à beira da lagoa, onde realizam toda cadeia produtiva do sururu.

Com relação à classificação profissional de pescadora, os interlocutores assim a usam para referir-se às mulheres que realizam a captura de peixes com redes (reducho, tarrafa, candango) e, ou, linha de anzol. Além desses instrumentos, a pescadora é a que realiza a pesca a qualquer hora do dia e de forma contínua, com o uso ou não de embarcações. Assim explica Marisa (50 anos, Ipioca) ao ser perguntada sobre a diferença entre marisqueira e pescadora: "Marisqueira tem os tempos dela andar, né? Para pegar isso aí, marisco, maçunim. E a pescadora não. São todos os dias, assim queira, né?”.

Em outra definição, Denise (46 anos, Trapiche da Barra) usa essa classificação profissional na forma masculina, para dizer o que vem a ser pescadora. "Pescador é diferente, porque pescador vai para a beira da lagoa, vai andar de canoa, é mais perigoso. Mas, quando a gente ia tirar, a gente tirava na beira [...], como daqui uns dez metros, tirar sururu". De acordo com Woortmann (1992), isso parece indicar que a pescadora se constrói a partir da identidade masculina, renegando ou tornando invisíveis as atividades realizadas pelas mulheres.

Características como perigoso, pesado, corajoso eram atribuídas ao homem que é pescador e, por consequência, à mulher cuja a atividade correspondesse a alguma dessas características. As mulheres que se comportavam assim, diante de seus pares, eram vistas como excepcionais, indicando que tal atividade não era algo para mulheres, conforme Ana (45 anos, Trapiche da Barra) comentou a respeito das percepçôes de outras pessoas sobre seu trabalho.

Entrevistador: $\mathrm{O}$ que as pessoas comentavam sobre as atividades que você fazia?

Ana: Às vezes, dizia assim: “Olha, a mulher parece um homem!".

Entrevistador: Hum.

Ana: Porque eu mergulhava, buscava sururu lá embaixo. E muitos não iam. Aí, diziam: "Vixe! Aquela mulher parece um homem!". Que sempre eu gostei de mergulhar. Eles diziam isso comigo na época.

Entrevistador: $\mathrm{Na}$ época, o que você achava disso?

Ana: Eu achava interessante eles disserem aquilo [...] Eles achavam que só o homem é que tinha coragem e a mulher não. Mas hoje as mulheres estão tomando os espaços dos homens (risos). Em quase todos os setores, né? 
Apesar de serem conhecidas e de se reconhecerem como pescadoras, alguns discursos mostravam o contrário. Assim, parecia ser no comentário de Tom (63 anos, Ipioca) sobre a distinção entre marisqueira e pescadora.

Tom: A pescadora mesmo é que nem na Barra de Santo Antônio; tem uma.

Entrevistadora: É?

Tom: Agora, ela vai para fora [...] com o marido. Aí pega, dá couro [...] . É peixe, ela pega mais do que ele. Não sei o que é, que a mulher parece pegar mais peixe que o homem. Não seio o que é. Só vendo [...]. Quando chega é com o barco cheio de peixe, mas é ela quem pega. Quer dizer que tem mulher pescadora.

Essa expressão "a pescadora mesmo" correspondia à atividade pesqueira realizada em alto-mar, espaço concebido como domínio masculino. Perspectiva distinta da encontrada no contexto das propostas políticas para o setor pesqueiro. Nas conferências estaduais e nacionais, a classificação pescadora também era usada para agregar a todas mulheres que trabalhavam no setor pesqueiro com finalidade de fortalecer esse grupo na reivindicação de seus direitos. Essas perspectivas demostravam que a classificação pescadora estava em construção (Goes, 2008).

Além da classificação pescadora, outras eram usadas no cotidiano das duas localidades. Essas foram as seguintes: "pescadeiras", "despinicadeiras", "sururuzeiras", "pombeiras", "marisqueiras", "maçuineiras", "mangueiras", "ostreicultoras" e "maricultoras". A princípio, "marisqueira" estava relacionada a qualquer atividade que as mulheres realizavam com marisco (sururu, o marisco redondo, o maçunim, caranguejo).

De acordo com o tipo de animal ou de atividade realizada, outras classificações foram usadas nas localidades de pesca. Betânia e Carolina eram reconhecidas como "pescadeiras de maçunim" e "maçuineiras" por realizarem atividades com o maçunim. O termo "marisqueira" foi associado a um outro molusco bivalve, diferente no tamanho e na cor das conchas, que comumente é conhecido como marisco redondo. Ao serem perguntadas sobre a diferença entre "marisqueira" e "maçuineira", elas esclareceram que:

Betânia: Maçunim é um. E marisco é outro, né?

Carol: É.

Betânia: O que é marisco, Carol?

Carol: Marisco é um bicho grande. Eu acho que é [...].

Betânia: Quem pega esse marisco é marisqueira, né, Carol? [...] (Betânia e Carolina, respectivamente, 40 e 30 anos - Ipioca). 
Situação parecida ocorreu no Trapiche da Barra, ao se classificarem as mulheres como "sururuzeiras". No entanto, essa não era substituta, mas sim apenas mais uma usada para designar as mulheres que trabalhavam com o sururu, sendo "marisqueira" a mais comum.

Assim também algumas mulheres eram denominadas "despinicadeiras", pois apenas efetuavam a limpeza do sururu, tiravam resquícios da lama e do bisso (estrutura de fixação desse molusco). A classificação "marisqueira" também era atribuída de acordo com a frequência da atividade realizada. Tal característica indicava o caráter profissional.

Com base nas observações feitas no cadastro profissional de associados e aposentados, as mulheres eram, geralmente, "marisqueiras" ou "pescadoras". $\mathrm{O}$ primeiro registro de mulher cadastrada naquela entidade data de 1984 e corresponde à classificação "marisqueira profissional". No entanto, ao longo do tempo, a colônia teve outros cadastros que foram sendo substituídos. O que convém dizer que esse dado não retrata o histórico de participação das mulheres desde o início de sua fundação, visto que muitos documentos não mais existem.

No ano de 1994, a classificação "pescadora" apareceu, pela primeira vez, acompanhada da palavra "profissional". Nessa década, várias classificações se fizeram presentes, tais como "pescador POP", "marisqueira profissional", "marisqueira POP", "marisqueira".

A década de 1990 pareceu configurar-se como um momento de efervescência da participação das mulheres no setor pesqueiro. Foi entre os anos de 1994 e 1999 que a atuação feminina ganhou espaço nas entidades representativas de classe. Isso foi constatado com base na diversidade de classificações encontrada nesse período no cadastro profissional.

Durante esse período, foi realizado um cadastro de homens e mulheres que atuavam no setor pesqueiro na colônia, conforme mencionado por Ana (45 anos, Trapiche da Barra). Esse consistiu na aplicação de um questionário contendo perguntas do dia a dia na pesca, como "você pesca o quê?", "como você pesca?".

Para esta interlocutora, as perguntas tinham como objetivo verificar se, de fato, aquelas pessoas trabalhavam na pesca. Em conversa com o presidente da colônia, esse cadastro foi realizado pela Capitania dos Portos e, como consequência, este resultou na concessão da carteira de aquaviário, que permitia a condução de embarcações de pesca nas vias marítimas e fluviais. Foi possível concluir que os anos de 1990 são de grandes avanços nas políticas públicas relacionadas à pesca, como a inserção da categoria "pescador artesanal" na Lei n. ${ }^{\circ} 8.212 / 1991$ e a regulamentação da prática pesqueira na Lei n. ${ }^{\circ}$ 9.605/1998. 
Nos anos de 2000, houve uma intensificação do uso da classificação "marisqueira", que apareceu sob as seguintes inscriçōes: "marisqueira artesanal", "marisqueira profissional". Essa intensificação parecia corresponder às repercussōes das políticas públicas que avançaram com a criação da SEAP/PR, em 2003, e a atuação dos movimentos de pescadores e pescadoras. As classificações "pescador artesanal", "pescador profissional" também foram usadas no cadastro para identificar as mulheres.

Com relação à participação das mulheres na colônia do Trapiche da Barra, observou-se que as mulheres buscavam realizar registro profissional, efetuar o pagamento das mensalidades como associados, de benefícios previdenciários, trabalhistas e financeiros e de confraternizar com seus pares. De modo geral, as mulheres estavam presentes nas atividades promovidas pela entidade.

A mulher tinha um papel importante na realização do cadastro profissional. Em sua maioria, mulheres e homens eram acompanhados por outras mulheres (vizinhas, parentes e, ou, acompanhantes da atividade pesqueira) que atuavam como incentivadoras. A atuação das mulheres não se restringia ao acompanhamento do futuro associado à colônia, mas também abrangia informações sobre os benefícios do cadastro. Esse aspecto foi percebido em Ipioca quando uma marisqueira convidou Simone ( 46 anos) para irem até o Município próximo realizar cadastro como marisqueira. No acaso específico dos homens, observou que esse papel era desempenhado por suas esposas e também estava relacionado ao pagamento de benefícios.

Além das mulheres atuarem no cadastro de seus pares, a diretoria da colônia tinha papel importante na identificação de homens e mulheres que atuavam no setor pesqueiro. Conforme mencionado por duas mulheres do Trapiche da Barra, o cadastro delas ocorreu por incentivo do secretário da colônia na época.

Em Ipioca, durante entrevista com Simone, o marido dela fez algumas considerações sobre a presença de organizaçōes, a exemplo das colônias, no reconhecimento do trabalho das marisqueiras.

Se aqui fosse que nem Maceió, né, Simone? Tivesse uma pesquisa [...] Tivesse uma pesquisa que dizer assim: "Não, vamos fazer o seguinte: vamos construir uma coisa que [...] Assalariado, como é que se diz? [...] Que a pessoa ganhasse alguma coisa, né? Tivesse alguma coisa. Por que é o seguinte: do jeito que está as coisa hoje em dia, a pessoa tem que fazer alguma coisa. E a comprovação é se você tá fichado ou se não tá. Que nem o pescador. O pescador paga aquela taxinha, mas tá comprovando que ele tá de documento assinado. É uma segurança. Já pra aqui não existe isso. Pra essas bandas daqui, não existe. Paripueira tem. Aqui em Ipioca é morto, ninguém vê essas coisas de Maceió (Vinícius, 50 anos, Ipioca). 
Nesse diálogo, Vinícius retratou a necessidade e a dificuldade de atuação de entidades representativas de classe no local. Sendo o bairro situado entre dois municípios de Alagoas, os moradores relatam situações em que se sentem abandonados pelo Poder Público. Apesar de pertencer a Maceió, Vinícius disse que nada foi feito pelo bairro, principalmente relacionado à pesca. Além disso, ele também relatou a necessidade de outras instituições, como a universidade, no desenvolvimento de pesquisas sobre a visibilidade da pesca e dos atores envolvidos nesta atividade.

A necessidade de uma entidade representativa de classe em Ipioca foi também sugerida no estudo de Ribeiro (2003), quando os pescadores e as pescadoras relataram que o funcionamento de uma colônia de pescadores local poderia contribuir para orientar e conscientizar os pescadores quanto à proteção do meio ambiente.

\section{REFLEXÕES FINAIS}

Há uma forte divisão sexual do trabalho no setor pesqueiro, cabendo aos homens as atividades mais valorizadas socialmente e de maior ganho monetário. A divisão sexual do espaço associa aos homens as atividades em alto-mar que são caracterizadas como aquelas que exigem coragem, força e bravura, e, consequentemente, somente pode ser realizada pelo homem pescador.

Não diferentes dos homens, as mulheres trabalham desde criança e participam de toda a cadeia produtiva do pescado: captura de espécies, beneficiamento do pescado e comercialização. Entretanto, por conta das relações sociais de sexo, as mulheres são destinadas prioritariamente às atividades que devem ser realizadas em associação ao trabalho doméstico. Iniciam suas atividades de pesca na praia, lagoa ou mangue e terminam no espaço doméstico. São jornadas intensas, condições difíceis, pouco ganho monetário e menos valoradas socialmente. Independentemente das atividades que elas realizam no setor pesqueiro, não são poupadas do trabalho doméstico. Fofocas e maledicências são usadas para que as mulheres não questionem a divisão sexual dos espaços na pesca.

Dada a divisão sexual do trabalho, as mulheres não são reconhecidas como pescadoras. Nas comunidades pesquisadas, diversas classificações são usadas para designar o trabalho das mulheres. Algumas mudanças podem ser vistas, especialmente fruto das organizações políticas das mulheres, a exemplo da Articulação Nacional de Mulheres Pescadoras, que tem politizado o debate sobre o trabalho das mulheres na pesca e influenciado as políticas públicas para o setor. A classificação profissional como pescadora tem um uso estratégico político que permite englobar todas as atividades das mulheres no setor pesqueiro e constitui- 
se como possibilidade de reconhecimento de seu trabalho, acesso a direitos trabalhistas, previdenciários e inclusão em políticas públicas de equidade de gênero. Em nível local, há organizações políticas de mulheres, e elas investem para que homens e mulheres realizem o cadastro profissional para a obtenção de direitos sociais, especialmente previdenciários.

Um aspecto do trabalho das pescadoras que é pouco comentado éa violência de gênero. As mulheres ficam vulneráveis à violência sexual, constroem alternativas de trabalho em grupo, entretanto não há, nas comunidades estudadas, políticas públicas que se contraponham à violência de gênero, especialmente a violência doméstica e sexual.

Sendo a pesca artesanal marcada por relações de parceria dentro e fora do grupo familiar, pôde-se destacar esse aspecto como uma forte estratégia no reconhecimento do trabalho das mulheres na pesca. Em Ipioca e no Trapiche da Barra, ao dividirem os espaços comuns de execução das atividades pesqueiras, as mulheres criam vínculos afetivos, constroem redes de apoio e de troca na qual compartilham suas vidas, socializam informações bem como incentivam umas às outras a se cadastrarem na colônia.

Uma das ações efetivas que poderiam ser realizadas parece ser o trabalho educativo e de mobilização junto às comunidades pesqueiras. $\mathrm{O}$ fortalecimento das organizações políticas de mulheres em nível local e da Articulação Nacional das Mulheres Pescadoras é um dos caminhos para a superação da hierarquia de gênero. Além disso, são necessárias políticas públicas estaduais e federal de fortalecimento do trabalho das mulheres com enfoque na equidade de gênero. 


\section{REFERÊNCIAS}

Alves, A. J. (1991). O planejamento de pesquisas qualitativas em educação. Cadernos de Pesquisa, 77, 53-61.

Diegues, A. C. (1983). Pescadores, camponeses e trabalhadores do mar. São Paulo: Ática.

Escallier, C. (1999). O papel das mulheres da Nazaré na economia haliêutica. Etnográfica, 3(2). Recuperado a partir de http://ceas.iscte.pt/etnografica/docs/ vol_03/n2/vol_iii_n2_293-308.pdf

Goes, L. O. (2008). Os usos da nomeação mulher pescadora no cotidiano de homense mulheres que atuam na pesca artesanal. (Dissertação de Mestrado). Universidade Federal de Pernambuco, Programa de Pós-graduação em Psicologia, Recife.

Guedes, N. (2007). Mulheres pescadoras tecendo novas redes. (Dissertação de Mestrado). Universidade Federal Rural de Pernambuco, Programa de Pósgraduação em Extensão Rural e Desenvolvimento Local, Recife.

Hirata, H. (2002). Nova divisão sexual do trabalho?: um olhar voltado para a empresa e a sociedade. São Paulo: Boitempo.

Hirata, H. \& Kergoat, D. (2003). A divisão sexual do trabalho revisitada. In M. Maruani \& H. Hirata (Orgs.), As novas fronteiras da desigualdade: homens e mulheres no mercado de trabalho. (pp. 111-123). São Paulo: Editora Senac.

Kergoat, D. (2000). Divisão sexual do trabalho e relações sociais de sexo. In H. Hirata, F. Laborie, H. Le Doaré \& D. Senoier (Orgs.), Dictionnaire critique du feminisme. (pp. 101-140). Paris: Presses Universitaires de France.

Kergoat, D. (2002). A relação social de sexo da reprodução das relações sociais à sua subversão. Pro-Posiçôes, 13(1), 47-59.

Lei no 8.212, de 24 de julho de 1991. (1991, 25 de julho). Dispõe sobre a organização da Seguridade Social, institui Plano de Custeio, e dá outras providências. Diário Oficial da União, Brasília. Recuperado a partir de http:// www.planalto.gov.br/ccivil_03/LEIS/L8212cons.htm

Lei $\mathrm{n}^{\circ}$ 9.605, de 12 de fevereiro de 1998. (1998, 13 de fevereiro). Dispóe sobre as sanções penais e administrativas derivadas de condutas e atividades lesivas ao meio ambiente, e dá outras providências. Diário Oficial da União, Brasília. Recuperado a partir de http://www.planalto.gov.br/ccivil_03/LEIS/L9605. htm 
Lima, C. M.\& Leitão, M. R. F. A. (2014). Transversalidade de gênero e políticas públicas na cadeia produtiva da pesca artesanal nas comunidades de Brasília Teimosa e Itapissuma (PE/Brasil). Vivência - Revista de Antropologia, 43, 123134.

Lima, J. P. (2003). Pescadoras e donas de casa: a invisibilidade do trabalho das mulheres numa comunidade pesqueira: o caso da Baía do Sol. (Dissertação de Mestrado), Universidade Federal do Pará, Programa de Pós-graduação em Sociologia, Belém.

Maneschy, M. C. (1995). A mulher está se afastando da pesca? Continuidade e mudança no papel da mulher na manutenção doméstica entre famílias de pescadores no litoral do Pará. Boletim do Museu Paraense Emílio Goeldi, 11(2), $145-166$.

Maneschy, M. C. (1999). Pesquisa e participação: relato de uma experiência com mulheres pescadoras do litoral paraense. In L. M. Álvares \& E. F. Santos (Orgs.), Olhares e diversidades: os estudos sobre gênero no norte e nordeste. (pp. 337-348). Belém: GEPEM/CFCH/UFPA, REDOR - N/NE.

Maneschy, M. C., Siqueira, D. \& Álvares, M. L. M. (2012). Pescadoras: subordinação de gênero e empoderamento. Estudos Feministas, 20(3), 713-737.

Maués, R. H. \& Motta-Maúes, M. A. (1990). Pesca e agricultura na Amazônia: a integração de uma comunidade rural ao modo de produção capitalista. Boletim do Museu Paraense Emílio Goeldi, 6(1), 29-40.

Motta-Maués, M. A. (1999). Pesca de homem/peixe de mulher (?): repensando gênero na literatura acadêmica sobre comunidades pesqueiras no Brasil. Etnográfica, 3(2), 377-399. Recuperado a partir de http://ceas.iscte.pt/ etnografica/docs/vol_03/N2/Vol_iii_N2_377-400_.pdf

Organização das Nações Unidas para a Alimentação e a Agricultura [FAO]. (2019). Programas no Brasil. Brasília: FAO. Recuperado a partir de http:// www.fao.org/brasil/programas-e-projetos/pt/

Ribeiro, M. A. T. (2003). A perspectiva dialógica na compreensão de problemas sociais: o caso da pesca de curral em Ipioca-Maceió-AL. (Tese de Doutorado), Pontifícia Universidade Católica de São Paulo, Programa de Pós-graduação em Psicologia Social, São Paulo. 
Sena, M. G. C. (2001). Onde o paraiso mostra seu avesso: cenas de trabalhadoras nas matas e mangues de Taperoá. (Dissertação de Mestrado). Universidade Estadual Paulista Júlio de Mesquita Filho, Programa de Pós-graduação em Sociologia, São Paulo.

Vieira, N. C., Siqueira, D., Gomes, M. \& Ever, M. (2015). Trabalho e gênero em comunidades extrativistas da costa paraense. Caderno Espaço Feminino, 28(1), 233-252.

Woortmann, E. F. (1992). Da complementariedade à dependência: espaço, tempo e gênero em comunidades "pesqueiras" do Nordeste. Revista Brasileira de Ciências Sociais, 18, 41-61. 